\title{
Factors Militating against the Delivery of Compassionate Care: A Malawian Perspective
}

\author{
Gladys Msiska, Andrew Simwaka, Berlington Munkhondya, Ezereth Kabuluzi, \\ Tiwonge Ethel Munkhondya
}

Kamuzu College of Nursing, The University of Malawi, Lilongwe, Malawi

Email: tiwongembeya@kcn.unima.mw

How to cite this paper: Msiska, G., Simwaka, A., Munkhondya, B., Kabuluzi, E. and Munkhondya, T.E. (2018) Factors Militating against the Delivery of Compassionate Care: A Malawian Perspective. Open Journal of Nursing, 8, 889-904. https://doi.org/10.4236/ojn.2018.812067

Received: October 24, 2018

Accepted: December 21, 2018

Published: December 24, 2018

Copyright ( 2018 by authors and Scientific Research Publishing Inc. This work is licensed under the Creative Commons Attribution International License (CC BY 4.0).

http://creativecommons.org/licenses/by/4.0/

\section{c) (i) Open Access}

\begin{abstract}
Background/Objectives: Malawi is one of the countries in the world with the worst maternal mortality rate. In view of this, women are encouraged to deliver at a health facility assisted by a skilled birth attendant. However, this initiative can only be effective when health care workers manifest a professional demeanor which conveys care and compassion to patients/clients. The objective of the study was to foster the development of compassionate care among nurses/midwives working in selected maternal and child health care clinical settings. Methods: The study employed an action research (AR) approach. Focus group discussions (FGDs) were conducted with nurse/midwives from the selected health facilities. Purposive sampling was utilized to obtain the sample of participants to the eight FGDs and thematic analysis was used to analyze the data. Results: The data collected from nurses/midwives clearly indicate that it is not possible to effectively render compassionate care under the present work conditions. The study reveals the following factors which hinder the delivery of compassionate care: severe nursing shortages, gross lack of essential supplies and equipment, negative attitudes of nurses/midwives and unsupportive leadership which demotivates nurses/midwives. Conclusion: The study reveals problems which hinder the delivery of compassionate care, and there is need to address these problems. This will enhance the effectiveness of hospital delivery by a skilled birth attendant as a safe motherhood initiative aimed at lowering the high maternal mortality rate.
\end{abstract}

\section{Keywords}

Compassion, Compassionate Care, Nursing/Midwifery Practice, Action Research

\section{Introduction}

Malawi is one of the countries in the world with the worst maternal mortality 
rate. Presently, Maternal mortality rate (MMR) is at 439 per 100,000 births, Neonatal mortality rate (NMR) is at 27 deaths per 1000 live births and infant mortality rate (IMR) is at 42 deaths per 1000 live births [1]. In view of this, women are encouraged to deliver at a health facility assisted by a skilled birth attendant. However, this initiative can only be effective when health care workers manifest a professional demeanor which conveys care and compassion to patients/clients. Compassionate care is a core and underpinning concept in nursing and midwifery practice and it is a moral obligation for all health care workers. Literature reflects declining standards of nursing and midwifery care in Malawi [2], and compassion seems to be a lost virtue among most nurses/midwives in Malawi [3]. Some media reports attest to the fact that negligence is quite rampant among health care workers in Malawi. However, such reports do not provide the health workers' perspective and more commonly they may perceive such as a blame game. Nurses and midwives constitute a critical mass of health care workers and their perspectives on the nature of care rendered should be explored. Furthermore, interventions to promote compassionate care practices should be informed by both patient and health care worker perspectives. To this end, this paper reports preliminary findings of an action research study whose aim is to foster the development of compassionate care among nurses/midwives working in selected health care facilities in Malawi. The findings reveal the nurses/midwives' perspectives on issues of compassionate care in Malawi.

\section{Study Design}

The study employed an action research (AR) approach. This is an inquiry which is done by or with insiders to an organization or community with an aim of addressing a problematic situation [4]. What set the impetus for this study is what J Paley [5] described as "compassion deficit" or "failure of compassion" which most of the nurses and midwives in Malawi seem to manifest towards patients/clients. This is a problem which is evidenced by incidents of negligence, dismissive attitudes of health care workers and other unprofessional misconducts which are commonly reported in the media. Waterman and Hope [6] assert that $\mathrm{AR}$ is a collaborative process between action researchers and participants or co-researchers where the co-researchers participate in all aspects of the action research. AR is participatory in nature requiring close collaboration with people who have a stake in the problems under investigation [4]. It involves a cycle of actions and in this study, the researchers collaborated and worked with nursing and midwifery staff to identify problems/needs and later devise plans to foster the development of compassionate care and evaluate the outcome. The findings reported in this paper are derived from the data which was collected from the nurse/midwives to develop an understanding of the problems associated with the provision of compassionate care within the selected health care facilities.

\subsection{Study Setting and Access to Participants}

The study took place at selected Health facilities in Malawi, where two of the fa- 
cilities were public hospitals, while one was a private hospital. It was implemented at antenatal, labour, postnatal, nursery and Paediatric units. The study explored compassionate care from the perspective of various stakeholders namely, nursing and midwifery staff, patients/relatives and nurse leaders. The various stakeholders constitute the "insider" and their input on matters of compassionate care provided the insider view. This paper reports part findings of the study and the sample from which data for these findings were collected were nurses/midwives.

\subsection{Data Collection}

Data were collected by the research team through focus group discussions (FGDs). Two focus group discussions were conducted at each of the four clinical settings and each FGD had eight nurse/midwives. In total we conducted eight FGDs and a total of 56 nurse/midwives participated. Potential participants were contacted in person by the research team and asked to participate in the FGDs at their respective health facilities. Each discussion lasted for an hour. Participants could discuss their perceptions on the nature of care which is rendered in their clinical facilities. The FGDs were digitally recorded and were transcribed by professional transcribers after deidentifying the data.

\subsection{Ethical Considerations}

Ethical approval for the study was obtained from the College of Medicine Research and Ethics Committee (COMREC) of the University of Malawi, and the reference number is P.03/16/1909. In addition, permission to conduct the study was sought from the three clinical facilities where the study took place and verbal and written consent were obtained from individual participants.

\subsection{Data Analysis}

Data coding and analysis followed the six steps thematic analysis by Braun and Clarke [7]. This is an approach to the analysis of qualitative data which allows for flexibility in the researchers' choice of theoretical framework and through its flexibility, it allows for rich, detailed and complex description of data. Initially, the transcripts were read several times to familiarise with the data, then the transcripts were manually coded by the three research team members who participated in the FGDs. Then all the related codes were grouped into potential themes. All the researchers reviewed the identified themes against the coded extracts and lastly, the researchers agreed on the naming of the themes.

\section{Findings}

This paper reports preliminary findings from the study which explored compassionate care from the perspectives of nurses/midwives who participated in the study. The findings reflect the nurse/midwives' descriptions of the nature of the care which is rendered and the factors which militate against the delivery of 
compassionate care. Five main themes have been formulated and the findings have been presented under these themes.

1) Description of the care: nurse/midwives' perspectives

The study findings reveal that more commonly, the care is compromised, and this was quite a constant theme. One of the nurse/midwives had this to say:

The care is not of a good quality because of other reasons such as shortage of staff, sometimes we do not have enough resources." (FGD-Dea 1-Participant \#8)

The failure to effectively render care is sometimes attributed to laziness and one participant expressed the following sentiments:

Sometimes it's just that people don't want to work, they don't want to give the care, they are lazy, they don't want to work, they are on the phones. That's what I have observed, [...] that's what I can see. (FGD-Paeds 1-Participant \#3)

Although more commonly care seems to be compromised, the study also reveals that some nurses are still committed, and they are trying their best despite the challenges. One of the nurses had this to say:

In our capacity as nurses, we feel we are trying our best because the work is overwhelming, and the staff are few, but we still try our best to provide the much-needed care for our patients. For example, in children's ward, we see that there is a decrease in death rate, so we feel that much as we are few, we still try our best to provide quality care which is supposed to be provided to our patients. (FGD-Paeds 2-Participant \#1)

The study also reveals factors responsible for improvements in care in some of the clinical settings like in the paediatric ward and nursery. One of the participants described it this way:

The other thing is about team work, in our ward we work as a team and this has helped to reduce the death rate. (FGD-Paeds 2-Participant \#3)

Likewise, another participant said:

I wanted to comment on how care is delivered especially in nursery. Its good and its adequate [...] But even if there is one person [nurse], you find that that one person is working all the time checking vital signs, giving the meds, you just don't find people sitting around in nursery. (FGD-Bwa 2-Participant \#3)

Furthermore, this is what was stated as the nature of care in nursery.

There is team work and people respect one another and the issue of attitude is not there. We don't just neglect babies, we don't just underestimate complaints from clients. We take each complaint. (FGD-Bwa 2-Participant \# 5)

2) Severe nursing shortage as a factor hindering the delivery of compassionate care 
The study reveals that one of the main factors compromising the quality of care is the shortage of nurses and the following excerpts illustrate this:

I think the quality has gone down because of several reasons. Number one is the shortage of nurses for example, today, I was alone in the antenatal clinic attending to initial visit clients. You know we must take history, so how can you do BP, weight, height and taking the history? I think you cannot manage like we used to do. Because we are supposed to be four nurses but instead, I was alone. (FGD-Eth 2-Participant \#7)

The study reveals nurse/midwives attending to many patients and working longer shifts than what is required due to the severe shortage of nurses. One of the participants had this to say:

The nurse to patient ratio is just high because the ideal one is 1 to 10 but you find that its 1 to 100 , how can one give quality care in that case? (FGD-Paeds 1-Participant \#6)

Another participant said:

On shortage of staff, sometimes we can find people working for maybe five days, day and night, day in day out [...] because there is no one to work for the other shift. It doesn't mean that we want to work but because that there is nobody to take that shift. (FGD-Eth 1-Participant \#6)

Likewise, another participant said:

When there is one nurse or there are two nurses, a friend can offer herself that even if it's my time to go home, let me stay with you so that I can help [...] Some of the nurses can be here [on a shift] for four days without going home because there is no one to work. So, they sacrifice themselves. (FGD-Eth 2-Participant \#3)

These findings illustrate the magnitude of the problem of shortage of nurses and midwives.

The study also reveals occurrence of patient safety issues due to poor monitoring of patients because of the severe shortage of nurses. Some critical incidents occur as a result of this where some patients die, or others nearly miss death. One of the participants made the following comment:

when you are working just the two of you in the labour ward, you conduct a delivery you are supposed to be monitoring that woman frequently and then it happens the patient develops BP [pre-eclampsia/eclampsia] so you don't know when, because sometimes you just deliver her and you just cover her up, you go to the next patient, or you have a patient in theatre [...] We had an incident where the patient could have died because she had PPH. (FGD-Eth 1-Participant \#4)

Another participant also had this to say: 
One night we had a client who had PPH and was attended to in theatre, the operation was done and the patient was supposed to go to the ward but then there was no nurse at the recovery room [...] then we went back to theatre with another emergency case, $[\ldots]$ we later found that the patient who was left at the recovery room had died. (FGD-Eth 1-Participant \#6)

Likewise, another participant had this to say:

My colleague was conducting another delivery and I was in theatre where we had four Caesarean sections [...] when I came back, the other woman had already delivered on her own and she had a big tear. (FGD-Eth 1-Participant \#2)

Furthermore, another participant said:

.... and sometimes that these women survive, is by grace of God, because it's really God's grace, you really have those risky incidences, so you just have to work where you can manage. (FGD-Eth 1-Participant \#1)

3) Gross lack of essential supplies and equipment as a factor hindering the delivery of compassionate care

The study also reveals that lack of resources and essential supplies is one of the hindering factors. Malawi being one of the poor countries most of the clinical settings lack materials and equipment. The following excerpt confirms that some drugs are not available sometimes and it states,

Some drugs are not available in pharmacy, and patients are told to buy, but some patients cannot manage, so they just stay without treatment. (FGD-Eth 2-Participant\#3)

Furthermore, another participant said:

Sometimes we run short of aprons, gloves, BP machines as of now we don't have BP machines and sometimes we are struggling in the antenatal with only one BP machine. (FGD-Bwa 2-Participant \#7)

The study provides evidence that the lack of resources is one of the factors compromising the quality of care. One of the participants had this to say:

Another thing that has contributed to poor care is lack of resources [...] you will move up and down to give care to somebody for example, in post-natal ward, there are many mothers with anaemia and during ward rounds we need to check the $\mathrm{HB}$ [haemoglobin level] using a hemoCue, which we don't have. So, I have to go looking for it from another ward. In the end you spend a lot of time without providing care. (FGD-Eth 2-Participant \#1)

Likewise, another participant said:

I think for me 1 would point out that the care is incomplete at our facility. I don't know if it is the whole nation, but at our facility the care is incomplete 
just because most of the times we lack resources. (FGD-Bwa 2-Participant $\# 1)$

Another participant had this to say:

So sometimes it is not the problem of nurses or the workers, but it is due to lack of resources, you are forced not to do something because you don't have any materials to do the procedure [...] so the care will be of low quality. (FGD-Dae1-Participant \#3)

4) Nurses and midwives' attitudes as a factor hindering the delivery of compassionate care

The study also provides evidence that nurses and midwives' attitudes are one of the factors hindering the delivery of compassionate care. One of the participants expressed the following sentiments:

Most of the times it's not about shortage of staff, but it's about our attitude [...] I don't know how to put it, but you'll find that if you go to the ward, and you find a lot of nurses. And then that there is a woman in the ward, who can't even breastfeed her child, she doesn't know how to put the baby on the breast, but the nurses are just sitting [...] women are not getting help, not because there is shortage of staff, but because us health service providers don't want to give the services to the women. (FGD-Bwa 2-Participant \#6)

The study reveals some of the factors which are responsible for poor attitudes of nurses and midwives towards patients and one of the participants had this to say:

I think it's very difficult to define what causes the attitude. To me, I think it's a personal trait. Sometimes people say it's because maybe you don't have a good relationship with your senior, or you are getting a low pay, or you have your own problems at home. All these things can contribute. Yeah, if I quarrel with my husband surely, all the women will be affected that day. Or if I don't have money, I'm so worried, or maybe my baby is sick... (FGD-Bwa 2-Participant \#6)

Another participant had this to say,

Sometimes the management [leaders] contributes to the poor attitudes of workers. The management is very tough on you, shouting, then you wonder, I am trying my best then you get discouraged. So, it hinders compassionate care. You are trying your best, but management is not appreciating what you are doing, always shouting at you... (FGD-Dae 1-Participant \#3)

Negative attitudes which nurses/midwives display sometimes hinder team spirit and leads to compromised care. The following excerpt illustrates this:

In the labour ward we have ten delivery rooms [...] And you find that you are put in rooms which are busy, and your other colleagues are at the 
nurses' station. When you ask them to assist, you find they will say "aah no it's not my room". So sometimes there is that challenge that other people [nurses] don't want to help you. (FGD-Bwa 2-Participant \#3)

The study also reveals that the unwillingness to help each other for nurse/midwives working in labour ward is due to fear of the Nurses \& Midwives Council if an incident has occurred. One of the participants had this to say:

People [nurse/midwives] are afraid of Nurses Council. So sometimes they are afraid to tackle issues because of Nurses Council. So, they say if I do go to that room, and that room does not belong to you, if there is a bad outcome, it means I will be implicated, and my licence will be withdrawn. So, we are afraid... (FGD-Bwa 2-Participant \#7)

Fear results from a perception that the Nurses \& Midwives Council always works against the nurse/midwives and the following excerpt illustrates this:

The way I perceive it, it's like when a nurse has done something wrong, or there is a case against the nurse, they [Nurses Council] are policing us, all the times they are on the negative side. That's why you see nurses they are always afraid [...] it's because of the way they handle us. They are like policing us and always they want to prove that the nurse is wrong. (FGD-Bwa 1-participant \#2)

The study reveals that the Nurses \& Midwives Council does not handle the nurse/midwives undergoing disciplinary hearings in a proper way and one of the participants expressed the following sentiments:

those who have been had incidents, they say when they are trying to find out the case, to investigate, the way they handle them, they are harsh. Yes, they are hard. (FGD-Bwa 2-Participant \#3)

The general feeling is that Council should change its approach, and this is how one of the participants puts it:

...It might be that you have done something wrong, but the way they will handle you it's so degrading. You just don't learn anything from that. You just get degraded and have no morale. And at the end they are taking away your certificate. You learn nothing. Yeah. Maybe they should change the approach. (FGD-Bwa 2-Participant \#7)

There is a general feeling among nurse/midwives that Nurses \& Midwives Council favours clients/patients and the study reveals that it should change its approach and consider the welfare of nurses and midwives. One of the participants had this to say:

...unless they [Nurses Council] hear that we don't learn anything by handling us that way they do, then they might reconsider and say well, let's do things in a different way all together. (FGD-Bwa 2-Participant \#9) 
5) Unsupportive leadership as a factor hindering the delivery of compassionate care

The study reveals lack of supportive supervision. Participants expressed lack of appreciation by their seniors which demotivates them.

Uh-mm. I feel our supervisors usually don't appreciate, they just come, and fault find $[\ldots]$ ah I don't know what I can say (...) (laughter). (FGD-Eth 2-Participant \#2)

Another participant said:

Yeah, like usually when someone has done something good, there is no praising or what, yeah, if someone is praised, she feels that "good...". (FGD-ETH 2-Participant \#5)

in fact, our management (leaders) does not appreciate. There are some nurses who are hard workers, but they are not appreciated. For instance, if there are trainings, they take those who are lazy... (FGD-Eth 2-Participant \#4)

Nurses expect that when there is severe nursing shortage during a shift, the ward in charge will assist in carrying out the various ward activities. However, the study reveals that some senior nurses seem to be so indifferent to the fact that there is severe nursing shortage. They conduct themselves in a manner that puts more strain on junior nurses. This is an area where lack of support is also perceived. One of the participants had this to say:

Registered nurses are ward managers, and sometimes they can just come in the ward the whole day they just using their phone [...] writing a roster or just on the phone; you are moving here and there, here and there and she is just seated working on the phone so it de-motivates somebody [junior nurses]. (FGD-Eth 2-Participant \#2)

Consequently, some junior nurses end up absenting themselves pretending that they are unwell. One of the nurses had this to say:

So, you are a junior, and she is your senior. And then next time you the junior now you say no, today am not coming am sick, because you are tired, uh-mm. But you are not sick, it's because you are tired. That's why care is going down because our seniors are the ones who have started being lazy. (FGD-ETH 2-Participant \#5)

\section{Discussion}

Compassion in the care of patients is highly valued but findings of the present study reveal that such care has been compromised either because of factors in healthcare settings where nurses practice or nurses' personal attributes. The study findings portray the nurse/midwives' perspectives on the nature of the care which is rendered. It reveals that care is not comprehensive, it is compromised and of a poor quality. These findings reveal what has been described in literature 
as "missed care", which is defined as a clinical situation where care is either not delivered, or not delivered on time [8]. Borneo and Helm [9] assert that when care is left "undone" there is a greater risk of death and in view of this, it is argued that in Malawi, missed care might be a possible reason for the high maternal, neonatal, infant, child and under-five mortality rates. Presently, Maternal mortality ratio (MMR) is at 439 per 100,000 births [1], while the neonatal mortality rate (NMR) is at 27 deaths per 1000 live births, infant mortality rate (IMR) is at 42 deaths per 1000 live births, and the under-five mortality rate is at 63 per 1000 live births [10].

Although care is compromised, and compassion seems to be a lost virtue, findings from this study show that some nurses are committed to their work and provide the much-needed care to patients, which has helped reduce child death rate at one of the studied hospitals. Furthermore, individual hard work in providing quality care was also reported in a nursery unit, where even when one nurse is on a shift, because of the critical shortage of nurses, the nurse would single handedly still be committed to carry out all the necessary activities, and hardly would the nurses be sitting around. Zamanzadeh, Valizadeh and Rahmani et al. [11] revealed that nurses look up to others as role models where they learn to act compassionately from their colleagues who are compassionate. These findings reveal that all hope is not lost, the nurses who demonstrate the passion to care despite the challenges are role models who are already there in practice. A study which was conducted in Iran revealed some individual factors and personal attributes such as participants' personal system of values and beliefs as an important factor that may influence the cultivation of compassion [12]. Debatably, it is the personal attributes which help to sustain the passion to care in such labour intense clinical settings. Being compassionate involves recognising and responding to a vulnerable individual with empathy [13] and some nurses in the study reported that they did not underestimate complaints from clients but took each complaint seriously and helped the clients accordingly. Nurses' teamwork helped provide quality care which resultantly reduced the death rate to significant levels. This is consistent with existing literature. Teamwork in nursing is perceived as being extremely important because when nurses work together, they forge the best outcomes for their patients [14]. Inherent in teamwork is peer-support and there is evidence that it enables compassion within care delivery [13].

The study reveals factors which act as barriers to the delivery of quality and compassionate care and these include: nursing shortage, lack of resources, nurse/midwives' attitudes and lack of supportive supervision. Nursing shortage is quite rampant in Malawi and it is therefore, a critical factor leading to poor nursing care, and indeed the failure to render compassionate care. In Malawi, the vacancy rates for Nursing Officers and Nurse Midwife Technicians are 66\% and $60 \%$ respectively [10]. One of the factors which led to the severe nursing shortage is the massive exodus of nurses to the UK which took place in early 2000s. This exacerbated Malawi's existing human resources crisis [15]. During 
this period Malawi lost a critical mass of registered nurse/midwives and it is argued that the country is still experiencing the effects of this exodus and the findings in this study portray such effects. Again, currently the government is not employing many new nurses due to economic problems and this has made the nurse shortage worse in the face of increasing health problems.

The participants' narratives reflect the magnitude of the nursing shortage in Malawi. There is evidence that one nurse can be responsible for taking care of up to 100 patients. Worse still, participants revealed that nurse/midwives sometimes work for four to five days, both day and night unintentionally. This portrays what Shipman and Hooten [16] described as mandatory overtime and it is associated with sleep deprivation, fatigue, and job dissatisfaction. Borneo and Helm [9] argue that when professionals give account of their own shifts, they cannot be overlooked. These findings portray the views of "insiders" [17], and as Bradley et al. [18] put it, understanding the situation from the health worker perspective can inform policy options that may contribute to a better working environment for staff and improved quality of care. It is argued that if the critical shortage of nurse/midwives in Malawi is not addressed, the safety of patients will be in jeopardy. Nursing shortage is said to compromise the patient safety and the quality of patient care [16]. Safe and effective staffing should be the goal of the health sector in Malawi and there is need to lobby for an increase in the staffing levels for all health care professionals. It is argued that safe staffing is one of the strategies that can significantly contribute towards the reduction of the high mortality rates in Malawi.

The critical incidents which have been reported illustrate how patient safety can be compromised because of the severe nursing shortage. For example, one of the excerpts reports an incident where a woman delivered on her own and had a big tear. The findings also report a case where a woman could have died and another case where a woman died. All these incidents occurred because the women were left unattended after delivery and they developed postpartum haemorrhage as the midwife was assisting another woman. Borneo and Helm posit that having the right number of appropriately qualified, competent and experienced nurses protect the public, but insufficient numbers of registered nurses have potentially life-threatening consequences for patients [9] and the findings in this study support this view.

The study also reveals that unsupportive leadership is one of the barriers to the delivery of compassionate care. Participants lamented at how the nursing leaders are quick to find faults and never convey any appreciation for the hard work which demotivates the nurses/midwives. An expression of appreciation is one of the factors that can motivate them, but there is evidence that it is never done. The infrequent supervision and support are problems which seem to have persisted over a long period of time as literature reveals [19] and it is one of the significant barriers to the delivery of compassionate care. This also is consistent with what Valizadeh et al. [12] revealed as organizational barriers to develop- 
ment of compassionate care in clinical practice. The authors assert that for compassionate care to flourish, policy makers, managers, and healthcare providers must foster an organizational atmosphere conducive to compassionate care [12]. Appreciation from nurse leaders conveys a sense of being valued and literature reveals that effective patient care requires a valued and rewarded nursing workforce [20]. Clark [21] also revealed that one of the factors which enable staff to be compassionate is to foster positive environments where staff are respected and feel valued and that their contribution is worthwhile. There is also evidence from previous studies that nurses who feel that they are supported or cared for by their supervisors, are not only more satisfied but also have higher levels of commitment [22] [23].

Nurse/midwives' attitudes are also a significant barrier to the delivery of compassionate care. It is difficult to determine what causes the attitudes, but this can be attributed to several factors some of which are personal, and others are organizational. However, it is argued that most of the causes are organizational factors. The argument purported here is that the nursing shortage, which is an organizational factor, can be responsible for negative health worker attitudes. Attitudes could also be attributed to burnout, and there is evidence from literature of its prevalence among Malawian nurse/midwives [2] [3]. Maslach ([24], p. 31) defined burnout as a process in which a professional's attitudes and behaviour change in negative ways in response to job strain. The severe nursing shortage which is prevalent in most clinical settings in Malawi is one of the factors that might cause job strain. Furthermore, lack of resources is one of the organizational factors which could also be responsible for health worker attitudes. It is a factor which can lead to moral distress, a concept which is defined as painful feelings and/or psychological disequilibrium that occurs in situations in which the ethically right course of action is known but cannot be acted upon ([25], p. 523). There is evidence of an association between moral distress and burnout [25].

The study further reveals that lack of supportive supervision is a factor which demotivates nurses and midwives, and it could also be responsible for negative health worker attitudes. Where there is no support from nurse/midwifery leaders, caring will also be the missing ingredient. This is problematic because it is said that when nurses feel cared about, they reciprocate the same to both co-workers and patients [26]. The study has also found that sometimes some nurses are not willing to help in Labour ward because if a woman died, they would also be reliable to punishment by Nurses and Midwives Council of Malawi, a regulatory body for nurses and midwives. This is also a factor which could be responsible for negative attitudes among nurses and midwives. The participants complained that the Council's current policy tends to favour patients more than staff in disciplinary cases. Meyer [27] in her commentary suggests that instead of focussing on poor performance and blaming practitioners, there is need for such regulatory associations to tease out what works and come up with realistic and achievable interventions in the context of staffs' busy schedules. There 
is a kind of a vicious cycle where organizational factors like shortage of staff and lack of support, just to mention a few, lead to negative attitudes which in turn lead to negative patient outcomes. It is argued that unless the afore mentioned organizational factors are addressed, poor health worker attitudes are likely to persist to the detriment of patient care. Valizadeh et al. [12] indicate that there is little understanding about how workplace issues impact on provision of compassionate care in nursing practice and the findings in this study illustrate this. The work place issues or organizational factors, more especially the severe nursing shortage which the study has revealed significantly contribute to what may be perceived as "compassion deficit" by those that are not "insiders". However, consistent with Gallgher [28], it is argued that care deficits which are commonly reported in the media may not be directly related to "compassion failure". More commonly, this can be attributed to the fact that there are too few staff and too many patients [18]. Fotaki [29] rightly points out that it is not just the absence of compassion by nurses per se that matters, but systematic implementation of relevant policies in the context of institutional healthcare is essential for embedding and cultivating compassionate attitudes in health professionals. Consequently, to foster the delivery of compassionate care and quality care, there is need for implementation of a safe staffing policy.

\section{Clinical Implications}

The nurse/midwives' perspective about the state of the care as it is rendered in the various clinical settings portrays a clear indication that it is not possible to effectively render compassionate care under the present circumstances. There is severe nursing shortage, and this is one of the important organizational factors or work force issues which is responsible for what is commonly perceived as "compassion deficit". There is a critical point of staffing levels below which poor quality of care can be expected or guaranteed. This is a problem which needs to be aggressively tackled. There is also unsupportive leadership and the study reveals that this demotivates the nurses and midwives and negatively impacts on their performance. All these factors are responsible for negative attitudes among nurses/midwives, a factor which is also revealed as a barrier to the delivery of compassionate care. There is need to address the reported organizational factors to effectively enhance the delivery of compassionate care. This will also help to mitigate the problem of negative attitudes among nurses/midwives and can also lead to restoration of the passion to care. It is argued that passion to care can be rediscovered and renewed. Compassionate, committed and emotionally sensitive leadership is required to have compassionate nurses/midwives [30].

\section{Strengths and Limitations}

This is the first study to explore compassionate care and the factors that hinder the implementation of compassionate care to patients in Malawi. The study findings reveal some of the critical challenges that need to be addressed if quality 
nursing/midwifery care is to be provided in Malawi. However, the study was only conducted in one district, the perspectives of hinderances to provision of compassionate found in this study might be different in other settings. Perhaps, a study to compare the understanding of compassionate care from different settings, may be required. Another limitation to the study could be that, since the research team members were nurse educators, which could have limited the participants to open up during the FGDs due to power imbalances. To limit such power imbalances, reflexivity was utilized. With reflexivity the researchers continuously remained self-aware of their role as researchers and thus, it enabled the researchers to gain trustworthy accounts from the participants [31].

\section{Acknowledgements}

We wish to acknowledge The Norwegian Programme for Capacity Development in Higher Education and Research for Development (NORHED) for funding the implementation of this research project. We also extent our gratitude to all the nurses/midwives who took part in the study.

\section{Conflicts of Interest}

The authors declare no conflicts of interest regarding the publication of this paper.

\section{References}

[1] National Statistical Office, ICF Macra (2017) Malawi Demographic and Health Survey 2015-2016. National Statistic Office, Zomba, Malawi and Rockville, Maryland, USA.

[2] Grigulis, A., Prost, A. and Osrin, D. (2009) The Lives of Malawian Nurses: the stories behind the Statistics. Transactions of the Royal Society of Tropical Medicine and Hygiene, 103, 1195-1196. https://doi.org/10.1016/j.trstmh.2009.03.005

[3] Msiska, G., Smith, P. and Fawcett, T. (2014) Emotive Responses to Ethical Challenges in Caring: A Malawian Perspective. Nursing Ethics, 21, 97-107.

https://doi.org/10.1177/0969733013487191

[4] Herr, K. and Anderson, G.L. (2014) The Action Research Dissertation: A Guide for Students and Faculty. Sage Publications, Thousand Oaks.

[5] Paley, J. (2013) Social Psychology and the Compassion Deficit. Nurse Education Today, 33, 1451. https://doi.org/10.1016/j.nedt.2013.05.011

[6] Waterman, H. and Hope, K. (2008) Action Research. In: Watson, R., McKenna, H., Cowman, S. and Kead, J., Eds., Nursing Research: Designs and Methods, Churchill Livingstone/Elsevier, Edinburgh, 211-220.

[7] Braun, V. and Clarke, V. (2006) Using Thematic Analysis in Psychology. Qualitative Research in Psychology, 3, 77-101. https://doi.org/10.1191/1478088706qp063oa

[8] Gibbon, B. and Crane, J. (2018) The Impact of 'Missed Care' on the Professional Socialisation of Nursing Students: A Qualitative Research Study. Nurse Education Today, 66, 19-24. https://doi.org/10.1016/j.nedt.2018.04.002

[9] Borneo, A., Helm, C. and Russell, J. (2017) Safe and Effective Staffing: Nursing Against the Odds. Royal College of Nursing, London. 
[10] Ministry of Health (2017) Health Sector Strategic Plan II 2017-2022: Towards Universal Health Coverage. Department of Health, Lilongwe.

[11] Zamanzadeh, V., Valizadeh, L., Rahmani, A., Cingel, M. and Ghafourifard, M. (2018) Factors Facilitating Nurses to Deliver Compassionate Care: A Qualitative Study. Scandinavian Journal of Caring Sciences, 32, 92-97. https://doi.org/10.1111/scs.12434

[12] Valizadeh, L., Zamanzadeh, V., Dewar, B., Rahmani, A. and Ghafourifard, M. (2018) Nurse's Perceptions of Organisational Barriers to Delivering Compassionate Care: A Qualitative Study. Nursing Ethics, 25, 580-590. https://doi.org/10.1177/0969733016660881

[13] Burridge, L.H., Winch, S., Kay, M. and Henderson, A. (2017) Building Compassion Literacy: Enabling Care in Primary Health Care Nursing. Collegian, 24, 85-91. https://doi.org/10.1016/j.colegn.2015.09.004

[14] Atefi, N., Abdullah, K.L. and Wong, L.P. (2016) Job Satisfaction of Malaysian Registered Nurses: A Qualitative Study. Nursing in Critical Care, 21, 8-17. https://doi.org/10.1111/nicc.12100

[15] Adhikari, R. and Grigulis, A. (2013) Through the Back Door: Nurse Migration to the UK from Malawi and Nepal, a Policy Critique. Health Policy Planning, 29, 237-245. https://doi.org/10.1093/heapol/czt010

[16] Shipman, D. and Hooten, J. (2008) Without Enough Nurse Educators There Will Be a Continual Decline in RNs and the Quality of Nursing Care: Contending with the Faculty Shortage. Nurse Education Today, 28, 521-523.

https://doi.org/10.1016/j.nedt.2008.03.001

[17] Blaikie, N.W.H. (2009) Designing Social Research: The Logic of Anticipation. 2nd Edition, Polity, Cambridge.

[18] Bradley, S., Kamwendo, F., Chipeta, E., Chimwaza, W., de Pinho, H. and McAuliffe, E. (2015) Too Few Staff, Too Many Patients: A Qualitative Study of the Impact on Obstetric Care Providers and on Quality of Care in Malawi. BMC Pregnancy and Childbirth, 15, 65. https://doi.org/10.1186/s12884-015-0492-5

[19] Muula, A.S., Panulo, B. and Maseko, F.C. (2006) The Financial Losses from the Migration of Nurses from Malawi. BMC Nursing, 5, 9.

[20] Horton, K., Tschudin, V. and Forget, A. (2007) The Value of Nursing: A Literature Review. Nursing Ethics, 14, 716-740. https://doi.org/10.1177/0969733007082112

[21] Clark, C. (2011) Why Civility Matters. Reflections on Nurse Leadership. Sigma Theta Tau.

[22] Shacklock, K., Brunetto, Y., Teo, S. and Farr-Wharton, R. (2014) The Role of Support Antecedents in Nurses' Intentions to Quit: The Case of Australia. Journal of Advanced Nursing, 70, 811-822. https://doi.org/10.1111/jan.12239

[23] Gelsema, T.I., Van Der Doef, M., Maes, S., Janssen, M., Akerboom, S. and Verhoeven, C. (2006) A Longitudinal Study of Job Stress in the Nursing Profession: Causes and Consequences. Journal of Nursing Management, 14, 289-299. https://doi.org/10.1111/j.1365-2934.2006.00635.x

[24] Maslach, C. (1982) Understanding Burnout: Definitional 1. Issues in Analyzing a Complex Phenomenon. In: Job Stress and Burnout: Research, Theory and Intervention Perspectives, Sage Publications, Beverly Hills, 111-124.

[25] Dalmolin, Gd.L., Lunardi, V.L., Lunardi, G.L., Barlem, E.L.D. and Silveira, R.S.D. (2014) Moral Distress and Burnout Syndrome: Are There Relationships between These Phenomena in Nursing Workers? Revista Latino-Americana de Enfermagem, 22, 35-42. https://doi.org/10.1590/0104-1169.3102.2393 
[26] Porter, O., Amp, A. and Grady, T. (2001) Profound Change: 21st Century Nursing. Nursing Outlook, 49, 182-186. https://doi.org/10.1067/mno.2001.112789

[27] Meyer, J. (2010) Promoting Dignity, Respect and Compassionate Care. Journal of Research in Nursing, 15, 69-73. https://doi.org/10.1177/1744987109353687

[28] Gallagher, A. (2015) Reflections on Compassion in Care. Nursing Ethics, 22, 843-844. https://doi.org/10.1177/0969733015619371

[29] Fotaki, M. (2015) Why and How Is Compassion Necessary to Provide Good Quality Healthcare? International Journal of Health Policy and Management, 4, 199-201. https://doi.org/10.15171/ijhpm.2015.66

[30] Smith, P. (2012) The Emotional Labour of Nursing Revisited: Can Nurses Still Care? 2nd Edition, Palgrave Macmillan, Basingstoke. https://doi.org/10.1007/978-0-230-35631-3

[31] McGee, R. (2002) The Self and Participatory Research. In: Brock, K. and McGee, R., Eds., Knowing Poverty: Critical Reflections on Participatory Research and Policy, Earthscan Publications Ltd., Sterling, 14-43. 